\title{
Plant hormones and their intricate signaling networks: unraveling the nexus
}

\author{
Prakash P. Kumar
}

Received: 23 March 2013/ Accepted: 24 March 2013/Published online: 30 March 2013

(C) Springer-Verlag Berlin Heidelberg 2013

The concept of hormones was developed by mammalian physiologists in the early nineteenth century. Etymologically, the word 'hormone' has its origins in the Greek verb ormao (ó $\rho \mu a ́ \omega$, meaning 'excite' or 'arouse') and was first used in 1905 by the British physiologist Ernest H. Starling (Henderson 2005). The idea of how specific chemical substances produced at defined locations (glands) and circulated in the body could profoundly affect growth, and development continues to fascinate scientists to this day.

Charles Darwin's idea of a 'transmissible influence' produced in the tips of coleoptiles formed the basis of decades of experimentation by plant physiologists culminating in the discovery and isolation of 'auxin' (Greek: auxein, to increase) as the first plant hormone in 1928 by Frits Warmolt Went (Went and Thimann 1937; Hopkins and Hüner 2009). The critical experiments were done from 1927 to 1933 by F.W. Went at the Royal Botanical Garden in Buitenzorg, Dutch East Indies (now Bogor, Indonesia) as continuation of his graduation thesis (1927) from the University of Utrecht, Holland (http://en.wikipedia.org/ wiki/Frits_Warmolt_Went). Subsequently, he joined Caltech, Pasadena, CA, USA and continued his work there. Although the effect of ethylene on plants was described by D.N. Neljubov prior to 1901, it was not until 1934 that R. Gane demonstrated ethylene to be a part of the volatile emission of plants. Hence, ethylene was recognized as a plant hormone only after that. Nearly, a century of work by various plant biologists has resulted in the elaborate knowledge base we now have on several groups of plant hormones.

P. P. Kumar $(\bowtie)$

Department of Biological Sciences, National University of Singapore, 10 Science Drive 4, Singapore 117543, Singapore e-mail: dbskumar@nus.edu.sg
The early studies were predominantly on the isolation, biosynthetic mechanisms and physiological actions of the major classes of plant hormones. Such studies have generated a solid foundation for the use of these compounds in agriculture and horticulture. Some of the notable applications of plant hormones include induction of flowering, fruit thinning, rooting in cuttings, and adventitious organogenesis or somatic embryogenesis in plant tissue culture. Nevertheless, doubts were aplenty as to whether these simple chemicals were indeed real hormones. This was mainly because of two factors: (1) the high degrees of pleiotropy exhibited by the various hormones in affecting numerous traits and (2) prior to the identification of specific receptors for the plant hormones, there was no convincing mechanism explaining the modes of action of these hormones.

In contrast, the field of plant hormone signaling has advanced at a furious pace during the last two decades after the discovery of the first plant hormone receptor, namely, that of ethylene (Chang et al. 1993). Since 1993, multiple receptors and scores of signaling intermediates have been identified for each class of plant hormones. It is firmly established now that plant hormones are perceived by specific receptors and the ensuing signaling networks regulate practically all aspects of plant growth and development. These discoveries have significantly and irrevocably changed how we study and understand the various growth and developmental processes in plants.

There are two main modes of signal transduction upon binding of the plant hormone to its receptor, namely, (1) proteasome-mediated degradation of intermediate repressor proteins leading to release of the steady-state repression (or activation) of selected transcription factors and (2) direct activation of downstream transcription factors (e.g., by protein phosphorylation) leading to induction of hormoneresponsive genes. A common theme connecting the two 
modes of signal transduction is the intricate crosstalk among the structurally unrelated signal initiator hormones. The elaborate crosstalk among the different hormones occurs at the biosynthesis and various downstream signaling intermediates (Stamm and Kumar 2010; Linkies and Leubner-Metzger 2012; Liu 2012). These findings are rapidly revealing the underlying complexity of molecular mechanisms by which plant hormones can elicit such a high degree of pleiotropic responses.

Therefore, when new themes for a special issue of the journal were being considered, plant hormone signaling emerged as a key subject. The response from the scientific community for a call to contribute to this special issue has been close to overwhelming. After stringent peer review selection, the final tally of manuscripts will fill two special issues - the first being general topics of hormone signaling, while the second issue will be articles dealing with abiotic and biotic stresses. The present issue has sixteen contributions ranging from how various groups of hormones initiate signal cascades to how hormone signals control differentiation of vascular tissues, seed germination, leaf and root development. Also included are papers on the physiology and toxicology of several hormone disrupting chemicals, the involvement of micro RNA, nitric oxide and phosphoglycerolipids and such molecules on hormone signaling. The contributions on the structural specializations of selected cytokinin signaling intermediates also help to highlight the highly interdisciplinary nature of the research being undertaken in the field. I thank all the contributors for their excellent cooperation and timely revisions to the manuscripts. Furthermore, it would not have been possible to put together the special issue without the wonderful support from the Editorial office of Plant Cell Reports and I gratefully acknowledge their help.

Exciting new findings continue to be made about the complex interactions among various hormones. Work on plant hormone signaling intermediates holds tremendous promises for introducing high levels of crop productivity in the future (Stamm et al. 2011). For example, we now know that inadvertent selection of altered gibberellin signaling intermediates by breeders was responsible for the production of dwarf and semi-dwarf hybrid plants that gave us the tremendous yield gains of the green revolution crops. It is abundantly clear that plant hormone signals do not just follow the three colors of traffic control signals, but involve the full spectrum of the rainbow in all its glory. It is hoped that the state-of-the-art treatments of the signaling-related topics in this special issue will be a modest and timely contribution for a field that promises to remain on the center stage in plant biology and shine brightly for several decades to come.

\section{References}

Chang C, Kwok SF, Bleecker AB, Meyerowitz EM (1993) Arabidopsis ethylene-response gene ETR1: similarity of product to twocomponent regulators. Science 262:539-544

Henderson J (2005) Ernest Starling and 'Hormones': an historical commentary. J Endocrinol 184:5-10. doi:10.1677/joe.1.06000

Hopkins WG, Hüner NPA (2009) Introduction to plant physiology, 4th edn. Wiley, Hoboken, pp 305-371

Linkies A, Leubner-Metzger G (2012) Beyond gibberellins and abscisic acid: how ethylene and jasmonates control seed germination. Plant Cell Rep 31:253-270

Liu Y (2012) Roles of mitogen-activated protein kinase cascades in ABA signaling. Plant Cell Rep 31:1-12

Stamm P, Kumar PP (2010) The phytohormone signal network regulating elongation growth during shade avoidance. J Exp Bot 61:2889-2903

Stamm P, Ramamoorthy R, Kumar PP (2011) Feeding the extra billions: strategies to improve crops and enhance future food security. Plant Biotech Rep 5:107-120. doi:10.1007/s11816-0110169-0

Went FW, Thimann KV (1937) Phytohormones. The Macmillan Company, New York, p 294. (www.biodiversitylibrary.org/item/ 26595\#page/14/mode/1up) 